\title{
Performance Improvement Strategy With Malcolm Baldrige Method Integration and SWOT Analysis (Case Study at UD. Syaiful Plastik)
}

\section{Strategi Peningkatan Kinerja Dengan Integrasi Metode Malcolm Baldrige Dan Analisis SWOT (Studi Kasus di UD. Syaiful Plastik)}

\author{
$1^{\text {st }}$ Mohammad Aji Prasetyo ${ }^{1}, 2^{\text {nd }}$ Hana Catur Wahyuni ${ }^{2}$ \\ \{prasetyoaji304@gmail.com ${ }^{1)}$, hanacatur@umsida.ac.id ${ }^{2}$ \}
}

Program Studi Teknik Industri, Universitas Muhammadiyah Sidoarjo, Indonesia

\begin{abstract}
There are problems that faced at UD. Syaiful Plastik including in the sector of leadership, measurement management, and company product output. This results in the quality and quantity of the company's products not being able to fulfill consumer expectations. To follow up on this problem, the Malcolm Baldrige method is used to analyze the company's performance with seven categories of assessment and SWOT analysis to determine the factorc that affect the company's performance, by assessing internal factors (strenghts and weaknesses), external factors (opportunities and threats). From the measurement results, Malcolm Baldrige's total score is 474 points with an overall percentage of $47 \%$ from a maximum score of 1000 . This value is at the average level including the early improvement category (point scale 376-475). The results of the internal evaluation contained 8 attributes of strength elements and 4 attributes of weakness elements. The results of the external evaluation contained 5 opportunity attributes and 5 threat attributes. Mapping the IFE-EFE matrix followed by a SWOT analysis resulted in 4 alternative strategies that can be done to build progress and a more competitive company advantage.
\end{abstract}

Keywords - Polypropylene Plastic, Performance Improvement, Malcom Baldrige, SWOT

Abstrak Permasalahan yang dihadapi di UD. Syaiful Plasik diantaranya pada bidang kepemimpinan, manajemen pengukuran, dan output produk perusahaan. Hal ini mengakibatkan kualitas dan kuantitas produk perusahaan tidak dapat memenuhi ekspektasi konsumen. Untuk menindaklanjuti masalah tersebut digunakan metode Malcolm Baldrige untuk menganalisa kinerja perusahaan dengan tujuh kategori penilaian dan analisis SWOT untuk mengetahui faktor yang berpengaruh terhadap kinerja perusahaan, dengan menilai faktor internal (kekuatan dan kelemahan), faktor eksternal (peluang dan ancaman). Dari hasil pengukuran didapatkan total skor Malcolm Baldrige sebesar 474 poin dengan persentase keseluruhan 47\% dari skor maksimal 1000. Nilai tersebut pada level average termasuk kategori early improvment (skala poin 376-475). Hasil evaluasi internal terdapat 8 atribut elemen kekuatan dan 4 atribut elemen kelemahan. Hasil evaluasi eksternal terdapat 5 atribut peluang dan 5 atribut ancaman. Pemetaan matriks IFE-EFE dilanjutkan analisis SWOT menghasilkan 4 alternatif setrategi yang dapat dilakukan untuk membangun kemajuan dan keunggulan perusahaan yang lebih kompetitif.

Kata Kunci - Plastik Polypropylene, Peningkatan Kinerja, Malcom Baldrige, SWOT

\section{Pendahuluan}

UD. Syaiful Plastik adalah perusahaan yang bergerak di industri plastik polypropylene, perusahaan ini berdiri sejak sekitar tahun 2012, usaha yang awal kegiatan produksinya hanya bergerak di bidang penyablonan dan pemotongan plastik berjenis PP (Polypropylene), HDPE (High Density Polyethylene) dan OPP (Oriented Polystryrene).

Identifikasi permasalahan yang terjadi di UD. Syaiful Plastik pada bidang kepemimpinan kurang adanya konsistensi dan ketegasan pimpinan mengenai aturan serta visi misi perusahaan sehingga karyawan kurang disiplin dalam melaksanakan pekerjaannya dan juga seringkali terjadi miskomunikasi antara pimpinan dengan karyawan, imbas dari permasalahan tersebut berdampak ke bidang manajemen pengukuran dan produksi mengakibatkan ketidaksesuaian produk yang dihasilkan serta minimnya pengetahuan teknologi yang mempengaruhi kualitas dan kuantitas produk untuk memenuhi ekspektasi konsumen. Dalam penelitian ini mencoba menerapan metode Malcolm Baldrige dan analisis SWOT karena dalam identifikasi permasalahan penelitian ini beberapa aspek permasalahan perusahaan sesuai dengan kriteria-kriteria yang ada pada metode yang akan digunakan sehingga penyelesaian masalahnya dapat menghasilkan alternatif strategi mengenai pengukuran serta perbaikan kinerja di perusahaan tersebut.

\section{Kinerja}

Kinerja yaitu suatu keberhasilan individu, tim, kelompok atau suatu unit organisasi untuk mencapai target strategi yang telah ditetapkan sebelumnya dengan proses kerja yang diinginkan. Kinerja perusahaan adalah suatu yang diperoleh dalam suatu perusahaan dengan jangka waktu dan durasi yang ditetapkan sebagai acuan pada standar awal yang telah ditentukan. Pengukuran kinerja adalah suatu kegiatan proses pencatatan, pengukuran dalam pelaksanaan 
kegiatan tertentu dengan menghasilkan suatu pencapaian misi perusahaan atau organisasi melalui data yang dapat ditampilkan untuk mengetahui hasil dari suatu produk, jasa dan proses produksi [1].

Ada tiga faktor yang mempengaruhi karyawan atau pegawai dalam melaksanakan pekerjaannya yaitu:

1. Faktor individu

Faktor individu merupakan faktor kemampuan dan keterampilan dalam menyelesaikan pekerjaannya. Kompetensi setiap seseorang biasanya berbeda-beda karena dipengaruhi beberapa faktor yang dapat digolongkan kedalam dua kelompok, yaitu kemampuan dan skill kerja serta motivasi dan etos kerja.

2. Faktor Organisasi

Dalam melaksanakan tugasnya, pegawai atau karyawan memerlukan dukungan organisasi tempatnya bekerja agar dapat memahami syarat-syarat dan aturan diperusahaan serta dapat menunjang kinerjanya. Dan berikut faktorfaktornya antara lain:

a. Pemahaman tentang kelompok organisasi

b. Penyediaan fasilitas kerja

c. Kenyamanan dan kondisi lingkungan kerja

d. Syarat ketentuan dan peraturan yang berlaku di perusahaan

Pengorganisasian ini dimaksudkan untuk memberi kejelasan tentang visi misi perusahaan bagi setiap pegawai atau karyawan agar dapat mencapai sasaran yang diinginkan oleh perusahaan, setiap individu dalam hal ini perlu serta wajib memiliki dan memahami peraturan agar bisa mempertanggung jawabkan tugas dan jabatannya dengan profesional.

3. Faktor Manajemen

Kinerja setiap orang memang berbeda-beda namun, perusahaan harus bisa mengatur dan mengarahkan agar sesuai dengan visi misi yang ingin dicapai perusahaan. Untuk mengaturnya dibutuhkan sistem pengorganisasian yang baik dan jelas, selanjutnya adalah menjelaskan tentang faktor manajemen. Dalam faktor ini diperlukan dukungan dari pihak manajemen atau pimpinan untuk mampu mengembangkan sistem dan hubungan industri ang aman dan harmonis, maupun mengembangkan kompetensi pekerja agar memiliki keterampilan yang tinggi dan juga mampu meningkatkan motivasi seluruh karyawan untuk bekerja secara optimal [2].

\section{METODE}

\section{A. Total Sampling}

Pengambilan sampling dalam penelitian ini dengan mengacu pada teknik total sampling, teknik total sampling adalah teknik pengambilan sampling yang memberikan peluang yang sama kepada seluruh anggota populasi untuk ditunjuk menjadi anggota sampel [3].

\section{B. Uji Validitas}

Uji validitas mengacu pada hasil yang diperoleh dari kuesioner, dengan hubungan Pearson Product Moment, yaitu korelasi antar item dengan total skor dalam satu variabel, dan pengukuran yang diperoleh menggunakan pemrograman SPSS dengan tingkat kepentingan $(\alpha)=0,05$ karena cukup mewakili, dan tingkat signifikansi biasa digunakan dalam penelitian ilmu sosial.

$$
r_{x y}=\frac{n \sum X_{\underline{i}} \underline{\underline{\underline{i}}}-\left(\sum X_{i}\right)\left(\sum \underline{\underline{i}}_{\underline{i}}\right)}{\sqrt{\left\{n \sum X_{i}^{2}-\left(\sum X_{i}\right)^{2}\right\}-\left\{n \sum Y_{i}^{2}-\left(\sum Y_{i}\right)^{2}\right\}}}
$$

Keterangan :

$$
\begin{array}{ll}
\mathrm{n} & =\text { Banyaknya data } \mathrm{X} \text { dan data } \mathrm{Y} \\
\sum \mathrm{X} & =\text { Jumlah total dari variabel } \mathrm{X} \\
\sum \mathrm{Y} & =\text { Jumlah total dari variabel } \mathrm{Y} \\
\sum \mathrm{X}^{2} & =\text { Kuadrat total dari total jumlah variabel } \mathrm{X} \\
\sum \mathrm{Y}^{2} & =\text { Kuadrat total dari total jumlah variabel } \mathrm{Y} \\
\sum \mathrm{XY} & =\text { Hasil perkalian dari total jumlah variabel } \mathrm{X} \text { dan variabel } \mathrm{Y}
\end{array}
$$

\section{Uji Reliabilitas}

Reliabilitas adalah strategi untuk memperoleh tingkat ketergantungan, konsistensi, dan kestabilan dari suatu pengukuran. Uji reliabilitas menggunakan persamaan Cronbach's Alpha. Cronbach's Alpha adalah rumus numerik yang digunakan dalam menguji tingkat kualitasukuran, di mana suatu instrumen dapat dianggap andal jika memiliki koefisien ketergantungan atau alpha 0,6 atau lebih. [4].

$$
r_{i}=\frac{k}{(k-1)}\left\{1-\frac{\sum \sigma_{b}^{2}}{\sigma_{t}^{2}}\right\}
$$




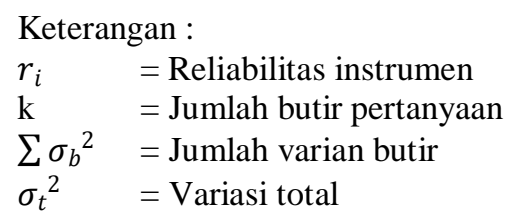

\section{Malcolm Baldrige}

Metode Malcolm Baldrige merupakan sebuah instrumen sistem pengujian menejemen yang difungsikan dalam menganalisa hasil kinerja perusahaan atau sebuah organisasi dengan 7 (tujuh) kategori cara penilaian. Metode ini dipublikasikan pada tahun 1987 oleh pemerintah Amerika Serikat untuk meningkatkan persaingan industri yang dimiliki pemerintah Amerika Serikat dengan legalnya US Public Law 100-107, dengan hal tersebut diterapkan dalam mendeteksi perusahaan yang menjadi pemimpin sebagai penyedia nilai dan kapasitas yang baik terhadap pelanggannya dalam kompetisi internasional [5].

Dalam Malcolm Baldrige disusun dengan gabungan tata nilai beserta konsep utama (Core Values and Concept) yang singkron erat satu dengan yang lainnya. Tata nilai dan konsep utama tersebut merupakan dasar untuk menggabungkan persyaratan bisnis inti ke dalam suatu konsep kerja berorientasi hasil (result-oriented framework) lalu dijadikan pusat untuk bertindak atau menerima timbal balik. Berikut ini ketujuh rancangan kriteria Malcolm Baldrige [6].

1. Kepemimpinan (120 poin)

2. Perencanaan Strategis ( 85 poin)

3. Fokus Pasar dan Pelanggan (85 poin)

4. Pengukuran, Analisis dan Manajemen Pengetahuan (90 poin)

5. Fokus Sumber Daya Manusia (85 poin)

6. Manajemen Proses (85 poin)

7. Hasil (450 poin)

Setelah dilakukan pengujian data dengan uji validitas dan uji reliabilitas selanjutnya dilakukan pengolahan data terhadap kategori penenelitian secara deskriptif dan matematis, skor Malcolm Baldrige pada tiap variabel kategori kuesioner menurut [7], diperoleh sebagai berikut:

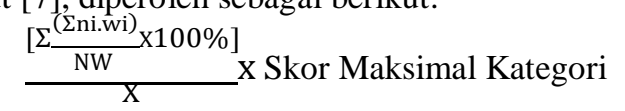

Keterangan :

ni = Jumlah pemilih jawaban i

wi = Bobot jawaban $\mathrm{i}$

$\mathrm{N}=$ Jumlah total respomden

$\mathrm{W}=$ Bobot jawaban terbesar

$\mathrm{X}=$ Jumlah total pertanyaan setiap kategori

\section{E. Analisis SWOT}

Analisis SWOT merupakan hasil analisa digunakan untuk memperoleh pengertian secara normal dari suatu organisasi atau perusahaan untuk menilai faktor internal dan eksternal yang mempengaruhi lembaga yang mungkin mempengaruhi kekuatan dan kelemahan dalam kaitannya dengan peluang serta ancaman yang terdapat pada lingkungan di suatu organisasi atau perusahaan. Persepsi ini berasal dari bahasa Inggris dan dipublikasikan sekitar tahun 1960-an sampai 1970-an di Amerika Serikat, kekuatan serta kelemahan berdasarkan pada elemen-elemen yang ada di dalam objek dalam kurun waktu tertentu, sedangkan peluang dan ancaman berkaitan dengan bagaimana kelak suatu organisasi atau perusahaan di masa depan dengan memiliki satu target atau tujuan. Analisis SWOT mempunyai beberapa keutamaan, namun juga memiliki beberapa kekurangan. Keutamaan dari analisis SWOT yaitu mempunyai kontribusi dalam memanfaatkan peluang, membangun kekuatan, membantu perencanaan strategis melalui informasi yang diberikan, membantu meminimalkan ancaman dan memanfaatkan peluang dan memanfaatkan keterampilan. Analisis SWOT merupakan pembahasan mengenai internal Strengths dan Weaknesses serta eksternal Oppurtunities dan Threats yang dialami dunia bisnis. Analisis tersebut didasarkan pada suatu logika untuk memaksimalkan kekuatan (Strengths) dan peluang (Oppurtunities), tetapi di sisi lain analisis tersebut juga dapat meminimalkan kelemahan (Weaknesses) dan juga ancaman (Threats). [8]. 
Procedia of Engineering and Life Science Vol. 1. No. 2 Juni 2021

Seminar Nasional \& Call Paper Fakultas Sains dan Teknologi (SENASAINS 2nd)

Universitas Muhammadiyah Sidoarjo

\section{Hasil dan Pembahasan}

Pengujian yang dilakukan dalam penelitian ini bertujuan untuk mengetahui nilai dari faktor-faktor kinerja yang ada diperusahaan dengan mengacu pada perhitungan menggunakan tujuh kriteria malcolm baldrige dan dapat menghasilkan strategi altertaif dengan analisis SWOT.

\section{A. Uji Validitas dan Reliabilitas}

Tabel 1. Hasil Uji Validitas

\begin{tabular}{|c|c|c|c|}
\hline & Variabel & r hitung & r tabel \\
\hline 1 & Kepemimpinan & 0,76 & 0,38 \\
\hline 2 & Perencanaan Strategis & 0,59 & 0,38 \\
\hline 3 & Fokus Pelanggan dan Pasar & 0,71 & 0,38 \\
\hline 4 & $\begin{array}{c}\text { Manajemen Pengukuran dan } \\
\text { Analisis }\end{array}$ & 0,64 & 0,38 \\
\hline 5 & Fokus Sumber Daya Manusia & 0,66 & 0,38 \\
\hline 6 & Manajemen Proses Operasional & 0,70 & 0,38 \\
\hline 7 & Kriteria Hasil & 0,67 & 0,38 \\
\hline
\end{tabular}

Dari tabel hasil uji validitas diatas maka data yang didapatkan dari penelitian ini dinyatakan valid, karena seluruh variabel memiliki nilai $r$ hitung $>r$ tabel [4].

Tabel 2. Hasil Uji Reliabilitas

\begin{tabular}{|c|c|c|c|}
\hline No & Variabel & $\begin{array}{c}\text { Cronch } \\
\text { Alpha } \\
\text { hitung }\end{array}$ & $\begin{array}{c}\text { Crounbach } \\
\text { Alpha }\end{array}$ \\
\hline 1 & Kepemimpinan & 0,616 & 0,6 \\
\hline 2 & Perencanaan Strategis & 0,603 & 0,6 \\
\hline 3 & Fokus Pelanggan dan Pasar & 0,660 & 0,6 \\
\hline 4 & Manajemen Pengukuran dan \\
Analisis & 0,638 & 0,6 \\
\hline 5 & Fokus Sumber Daya Manusia & 0,773 & 0,6 \\
\hline 6 & Manajemen Proses Operasional & 0,791 & 0,6 \\
\hline 7 & Kriteria Hasil & 0,788 & 0,6 \\
\hline
\end{tabular}

Dari tabel hasil uji reliabilitas diatas maka data yang didapatkan dari penelitian ini dinyatakan reliabel, karena seluruh variabel memiliki nilai Cronbach Alpha > 0,6 [4].

\section{B. Perhitungan Metode Malcolm Baldrige}

Contoh perhitungan untuk mendapatkan skor per kriteria diperoleh dengan cara sebagai berikut :

\section{Kepemimpinan}

Pernyataan $1.1=\underline{(1 \times 15)+(2 \times 7)+(3 \times 4)+(4 \times 1)}=0,42(42 \%)$

Pernyataan $1.1=\frac{(1 \times 13)+(2 x 8)+(3 \times 4)+(4 x 2)}{27 x 4}=0,45(45 \%)$

Pernyataan $1.1=\frac{(1 \times 9)+(2 \times 11)+(3 \times 5)+(4 \times 2)}{27 \times 4}=0,49(49 \%)$

Pernyataan $1.2=\frac{(1 \times 10)+(2 \times 10)+(3 \times 6)+(4 x 1)}{27 x 4}=0,49(49 \%)$

Pernyataan $1.2=\frac{(1 \times 12)+(2 x 7)+(3 \times 6)+(4 \times 2)}{27 x 4}=0,48(48 \%)$

Pernyataan $1.2=\frac{(1 \times 10)+\left(2 x^{2}\right)+(3446)+(4 \times 3)}{27 \times 4}=0,52(52 \%)$

$\left(\frac{285}{6}\right) \times 120=57$

Pada hasil perhitungan menunjukkan bahwa skor kuesioner untuk kategori kepemimpinan yang terdiri dari 6 pernyataan mendapatkan skor (57) poin atau 48\% dari skor maksimal untuk kategori ini yakni (120) poin. Kriteria komunikasi antara pimpinan dengan karyawan memiliki persentase tertinggi (52\%). Sedangkan kriteria yang memiliki pengetahuan mengenai visi perusahaan memiliki persentase $(42 \%)$. Selanjutnya yaitu melakukan rekapitulasi capaian skor dari seluruh kategori berdasarkan hasil kuesioner, seperti pada tabel dibawah ini. 
Procedia of Engineering and Life Science Vol. 1. No. 2 Juni 2021

Seminar Nasional \& Call Paper Fakultas Sains dan Teknologi (SENASAINS 2nd)

Universitas Muhammadiyah Sidoarjo

Tabel 3. Rekapitulasi Skor Seluruh Kategori Malcolm Baldrige

\begin{tabular}{|c|c|c|c|c|}
\hline Kategori & Item & $\begin{array}{l}\text { Skor } \\
\text { Max }\end{array}$ & $\begin{array}{c}\text { Skor } \\
\text { Diperoleh }\end{array}$ & $\begin{array}{l}\text { Persen } \\
\text { Capaian }\end{array}$ \\
\hline \multirow{2}{*}{ 1. Kepemimpinan } & $1.1 \mathrm{Kepemimpinan}$ Senior & \multirow{2}{*}{120} & \multirow{2}{*}{57} & \multirow{2}{*}{$48 \%$} \\
\hline & 1.2 Tata Kelola dan Tanggung Jawab Sosial & & & \\
\hline \multirow{2}{*}{$\begin{array}{l}\text { 2. Perencanaan } \\
\text { Strategi }\end{array}$} & 2.1 Pengembangan Strategi & \multirow{2}{*}{85} & \multirow{2}{*}{43} & \multirow{2}{*}{$51 \%$} \\
\hline & 2.2 Penyebarluasan Strategi & & & \\
\hline \multirow{2}{*}{$\begin{array}{l}\text { 3. Fokus Pelanggan } \\
\text { dan Pasar }\end{array}$} & 3.1 Pengetahuan Pelanggan dan Pasar & \multirow{2}{*}{85} & \multirow{2}{*}{43} & \multirow{2}{*}{$51 \%$} \\
\hline & 3.2 Hubungan dan Kepuasan Pelanggan & & & \\
\hline \multirow{2}{*}{$\begin{array}{l}\text { 4. Manajemen } \\
\text { Pengukuran dan } \\
\text { Analisis }\end{array}$} & $\begin{array}{l}\text { 4.1 Pengukuran, Analisis dan Peningkatan } \\
\text { Kinerja }\end{array}$ & \multirow{2}{*}{90} & \multirow{2}{*}{42} & \multirow{2}{*}{$46 \%$} \\
\hline & $\begin{array}{l}\text { 4.2 Manajemen Informasi, Teknologi dan } \\
\text { Pengetahuan }\end{array}$ & & & \\
\hline \multirow{2}{*}{$\begin{array}{l}\text { 5. Fokus Sumber Daya } \\
\text { Manusia }\end{array}$} & 5.1 Keterlibatan Karyawan & \multirow{2}{*}{85} & \multirow{2}{*}{42} & \multirow{2}{*}{$50 \%$} \\
\hline & 5.2 Lingkungan Tenaga Kerja & & & \\
\hline \multirow{2}{*}{ 6. Manajemen Proses } & 6.1 Desain Sistem Kerja & \multirow{2}{*}{85} & \multirow{2}{*}{44} & \multirow{2}{*}{$52 \%$} \\
\hline & 6.2 Manajemen dan Peningkatan Proses Kerja & & & \\
\hline \multirow{6}{*}{ 7. Kriteria Hasil } & 7.1 Outcome Produk dan Pelayanan & \multirow{6}{*}{450} & \multirow{6}{*}{203} & \multirow{6}{*}{$43 \%$} \\
\hline & 7.2 Outcome Berfokus Pelanggan & & & \\
\hline & 7.3 Outcome Finansial dan Pasar & & & \\
\hline & 7.4 Outcome Berfokus SDM & & & \\
\hline & 7.5 Outcome Evektivitas Proses & & & \\
\hline & 7.6 Outcome Kepemimpinan & & & \\
\hline \multicolumn{2}{|r|}{ TOTAL } & 1000 & 474 & $47 \%$ \\
\hline
\end{tabular}

Tabel 3. menunjukkan total skor yang diperoleh UD. Syaiful Plastik untuk seluruh kategori MBNQA berdasarkan hasil kuesioner adalah sebesar 474 poin atau (47\%) dari skor maksimal 1000 poin. Kategori dengan skor terbesar di dapat dari kategori hasil (203) poin. Sedangkan yang paling rendah adalah kategori manajemen pengukuran dan analisis (41) poin. Sementara untuk capaian, kategori dengan persentase terbesar adalah kategori manajemen proses yang memperoleh persentase (52\%) dan presentase terendah adalah kategori hasil yang memperoleh persentase (43\%).

Dari hasil total skor yang dicapai oleh UD. Syaiful Plastik sebesar (473) poin. Dengan skor tersebut dalam penilaian kinerja UD. Syaiful Plastik meraih predikat average dan termasuk dalam kategori early improvment (skala poin 376-475). Early improvment berarti UD. Syaiful Plastik berada dalam posisi perusahaan memiliki tahap awal pencapaian hasil yang baik dalam upaya mencapai kinerja excellent.

\section{Matriks Internal Factor Evaluation dan Eksternal Factor Evaluation (IFE dan EFE)}

Dalam melakukan pemberian rating skala nilai 1 (poor) dan 4 (outstanding) tergantung pada pengaruh faktor yang berpengaruh terhadap perusahaan. Untuk faktor kekuatan dan peluang dibarikan rating 1 (jika kekuatan dan peluangnya kecil) sampai dengan 4 (jika peluangnya semakin besar) dan untuk kelemahan dan ancaman diberi rating 1 (jika kelemahan dan ancamannya kecil) sampai dengan 4 (jika ancamannya semakin besar) [9].

Matriks Internal Factor Evaluation (IFE)

Dalam penentuan item kekuatan ini mengambil dari kategori-kategori Malcolm Baldrige di UD. Syaiful Plastik yang memiliki persentase pencapaian $\geq 50 \%$ dan item kelemahan mengambil dari kriteria dengan persentase $<50 \%$ yang dimiliki perusahaan [10].

Tabel 4. Faktor-Faktor Internal

\begin{tabular}{|c|l|c|c|c|}
\hline \multicolumn{1}{|c|}{ No } & \multicolumn{1}{|c|}{ Pertanyaan } & $\begin{array}{c}\text { Bobot } \\
(\mathbf{B})\end{array}$ & $\begin{array}{c}\text { Rating } \\
(\mathbf{R})\end{array}$ & $\begin{array}{c}\text { Skor } \\
(\mathbf{B x R})\end{array}$ \\
\hline Strength (Kekuatan) & 0,13 & 3,25 & 0,43 \\
\hline S1 & Pengembangan Strategi & 0,12 & 3,00 & 0,36 \\
\hline S2 & Penyebarluasan Strategi & 0,14 & 3,75 & 0,54 \\
\hline S3 & Pengetahuan Pelanggan dan Pasar & 0,13 & 3,25 & 0,43 \\
\hline S4 & Hubungan dan Kepuasan Pelanggan & 0,11 & 3,25 & 0,35 \\
\hline S5 & Keterlibatan Karyawan & 0,13 & 3,75 & 0,50 \\
\hline S6 & Lingkungan Tenaga Kerja & 0,12 & 3,25 & 0,39 \\
\hline S7 & Desain Sistem Kerja & 0,11 & 3,25 & 0,35 \\
\hline S8 & Manajemen dan Peningkatan Proses Kerja & $\mathbf{1}$ & & $\mathbf{3 , 3 6}$ \\
\hline \multicolumn{2}{|c|}{ Jumlah } & & &
\end{tabular}


Procedia of Engineering and Life Science Vol. 1. No. 2 Juni 2021

Seminar Nasional \& Call Paper Fakultas Sains dan Teknologi (SENASAINS $2^{\text {nd }}$ )

Universitas Muhammadiyah Sidoarjo

\begin{tabular}{|l|l|c|c|c|}
\hline Weaknesses (Kelemahan) & 0,26 & 3,75 & 0,98 \\
\hline W1 & Kepemimpinan Senior & 0,24 & 3,25 & 0,78 \\
\hline W2 & Tata Kelola dan Tanggung Jawab Sosial & 0,26 & 3,5 & 0,91 \\
\hline W3 & Pengukuran, Analisis dan Peningkatan Kinerja & 0,24 & 3,5 & 0,84 \\
\hline W4 & Manajemen Informasi, Teknologi dan Pengetahuan & $\mathbf{1}$ & & $\mathbf{3 , 5 1}$ \\
\hline \multicolumn{3}{|c|}{ Jumlah } & & $\mathbf{- 0 , 1 5}$ \\
\hline
\end{tabular}

\section{Matriks Eksternal Factor Evaluation (EFE)}

Analisa faktor eksternal perusahaan berdasrkan analisa pasar, pemasok, perusahaan pesaing, keadaan sosial, perekonomian dan pelanggan maka diketahui peluang dan ancaman yang ada di perusahaan [10].

Tabel 4.18 Rekapitulasi Hasil EFAS

\begin{tabular}{|c|c|c|c|c|}
\hline No & Pertanyaan & $\begin{array}{c}\text { Bobot } \\
\text { (B) }\end{array}$ & $\begin{array}{c}\text { Rating } \\
\text { (R) }\end{array}$ & $\begin{array}{c}\text { Skor } \\
(\mathrm{BxR})\end{array}$ \\
\hline \multicolumn{5}{|c|}{ Opportunity (Peluang) } \\
\hline $\mathrm{O} 1$ & Plastik merupakan kemasan yang umum digunakan di indonesia & 0,20 & 3,5 & 0,71 \\
\hline $\mathrm{O} 2$ & Tidak ada pabrik pesaing di wilayah tersebut & 0,20 & 3,5 & 0,71 \\
\hline $\mathrm{O} 3$ & Harga terjangkau dari distributor lain & 0,19 & 3,25 & 0,61 \\
\hline $\mathrm{O} 4$ & Banyaknya mitra usaha & 0,20 & 3,75 & 0,76 \\
\hline $\mathrm{O5}$ & Tingginya permintaan plastik kemasan & 0,20 & 3,75 & 0,76 \\
\hline \multicolumn{2}{|r|}{ Jumlah } & 1 & & 3,56 \\
\hline \multicolumn{5}{|c|}{ Threat (Ancaman) } \\
\hline $\mathrm{T} 1$ & Adanya kampanye untuk mengurangi penggunaan plastik & 0,19 & 3,25 & 0,63 \\
\hline $\mathrm{T} 2$ & Teknologi di perusahaan pesaing lebih modern & 0,21 & 3,25 & 0,68 \\
\hline $\mathrm{T} 3$ & Persaingan kualitas produk dengan perusahaan lain & 0,21 & 3,25 & 0,68 \\
\hline $\mathrm{T} 4$ & Brand perusahaan pesaing lebih terkenal & 0,21 & 3,25 & 0,68 \\
\hline $\mathrm{T} 5$ & Marketing perusahaan lebih luas & 0,18 & 3,25 & 0,59 \\
\hline & Jumlah & 1 & & 3,25 \\
\hline \multicolumn{4}{|c|}{ Opportunity - Threat (O-T) } & $\mathbf{0 , 3 1}$ \\
\hline
\end{tabular}

Dari tabel diatas dapat diketahui bahwa nilai internal faktor strategi (S-W) sebesar -0,15 dan nilai eksternal faktor strategi (O-T) sebesar 0,31. Kemudian untuk menentukan strategi kelanjutannya dapat menggunakan diagram SWOT berikut.

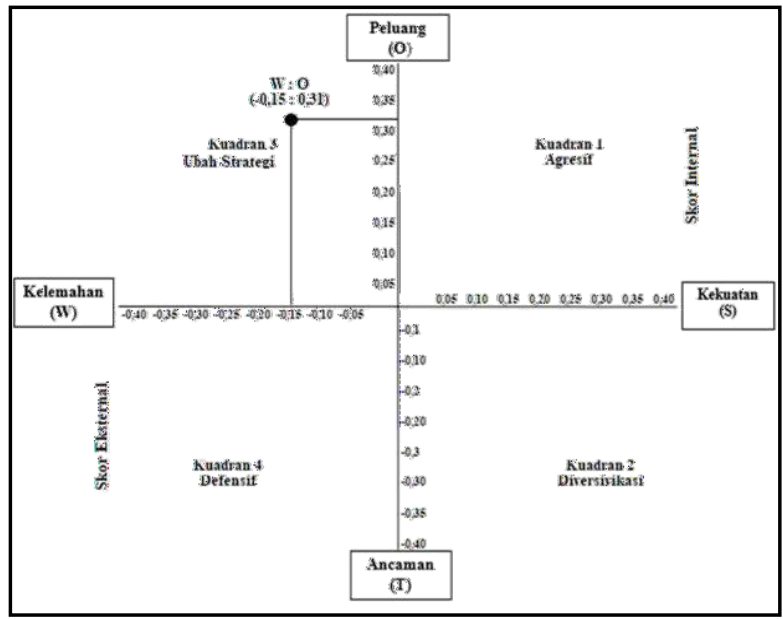

Gambar 1. Diagram SWOT

Dari hasil diagram SWOT diatas, dapat dianalisa bahwa posisi UD. Syaiful Plastik berada pada posisi kuadran 3 yang artinya perusahaan tersebut dapat meminimalisir kelemahan internal dengan memanfaatkan peluang-peluang, upaya yang dapat dilakukan yaitu mengubah strategi perusahaan dan strategi yang dapat dilakukan yaitu menggunakan strategi (W-O). Startegi ini dapat meminimalisir kelemahan-kelemahan internal yang ada di perusahaan dengan cara memanfaatkan peluang-peluang yang ada. 


\section{KESIMPULAN}

SWOT.

Berikut adalah kesimpulan dari hasil penelitian dengan menggunakan metode Malcolm Baldrige dan analisis

1. Berdasarkan hasil kategori Kepemimpinan yang terdiri dari enam kriteria mendapatkan persentase rata-rata sebesar (48\%) dan total skor kategori sebesar (57) poin dari total maksimal (120) poin. Kategori Perencanaan Strategis yang terdiri dari lima kriteria mendapatkan persentase rata-rata sebesar (51\%) dan total skor kategori sebesar (43) poin dari total maksimal (85) poin. Kategori Fokus Pelanggan dan Pasar yang terdiri dari lima kriteria mendapatkan persentase rata-rata sebesar (51\%) dan total skor kategori sebesar (43) poin dari total maksimal (85) poin. Kategori Manajemen Pengukuran dan Analisis yang terdiri dari enam kriteria mendapatkan persentase rata-rata sebesar (46\%) dan total skor kategori sebesar (41) poin dari total maksimal (90) poin. Kategori Fokus Sumber Daya Manusia yang terdiri dari enam kriteria mendapatkan persentase rata-rata sebesar (50\%) dan total skor kategori sebesar (42) poin dari total maksimal (85) poin. Kategori Manajemen Proses Operasional yang terdiri dari empat kriteria mendapatkan persentase rata-rata sebesar (52\%) dan total skor kategori sebesar (44) poin dari total maksimal (85) poin. Kategori Hasil yang terdiri dari sembilan kriteria mendapatkan persentase rata-rata sebesar (45\%) dan total skor kategori sebesar (203) poin dari total poin maksimal (450). Berdasrkan hasil perhitungan presentase dan skor seluruh kategori yang digunakan dalam pengukuran metode Malcolm Baldrige didapatkan total skor yaitu sebesar 474 poin dengan persentase pencapaian keseluruhan sebesar 47\% dari skor maksimal 1000 . Dari skor tersebut dalam penilaian kinerja di UD. Syaiful Plastik meraih predikat average dan termasuk dalam kategori early improvment (skala poin 376-475). Early improvment berarti UD. Syaiful Plastik berada dalam posisi perusahaan memiliki tahap awal pencapaian hasil yang baik.

2. Hasil perbaikan strategi dengan menggunakan analisis SWOT didapatkan nilai Strenght (kekuatan) - Weaknesses (kelemahan) sebesar (-0,15). Sedangkan dalam nilai Opportunity (peluang) - Threat (ancaman) sebesar $(0,31)$. Jadi, dalam diagram strategi SWOT hasil pengukuran kinerja di UD. Syaiful Plastik berada pada posisi kuadran 3 (ubah strategi). Sehingga dalam upaya perbaikan strategi perusahaan lebih ideal menggunakan strategi Weaknesses - Opprtunity (WO) karena jika dilihat dari identifikasi permasalahan perusahaan, startegi ini dapat meminimalisir kelemahan-kelemahan internal yang ada di perusahaan dengan cara memanfaatkan peluang-peluang yang ada. Untuk alternatif perbaikannya dapat dilakukan dengan cara :

a. Pimpinan menjalin kerjasama dengan pihak perusahaan lain yang bertujuan untuk meningkatkan kualitas SDM, pengetahuan dan teknologi perusahaan.

b. Melakukan pendekatan-pendekatan kontrak kerjasama dengan perusahaan lain yang membutuhkan produk plastik.

c. Mengembangkan inovasi dan kualitas produk agar lebih bisa bersaing dengan brand lain.

d. Membuat indikator kinerja karyawan agar perusahaan bisa menganalisa hasil kinerja dengan akurat. 


\section{REFERENSI}

[1] Susanto, Edi, “Analisis Pendekatan Malcolm Baldrige Criteria For Performanc Excellence (MBCFPE) Terhadap Kinerja Di PT. Kinenta Indonesia," Institut Teknologi Nasional (ITENAS) Bandung, Jurnal Sistem Teknik Industri, vol. 19, pp.1-6, 2017.

[2] Devita, Maria, "Faktor-Faktor Yang Memepengaruhi Kinerja Karyawan Restaurant Alpha Hotel Pekan Baru". Institut Teknologi Nasional (ITENAS) Bandung,” JOM FISIP, vol.4, no.2, pp.1-15, 2017.

[3] Kasmini, Lili dan Nirwanasari Purba, "Pengaruh Eksperimen Sains Pada Materi Mencampur Warna Terhadap Perkembangan Kognitif Anak Kelompok B2 Pada TK Pertiwi Banda Aceh”. STKIP Bina Bangsa Getsempena. Prodi PG PAUD, vol.III, no.1, pp. 31-42, 2016.

[4] Zahra, Ratika R dan Nofha Rina, "Pengaruh Celebrity Endorser Hamidah Rachmayanti Terhadap Keputusan Pembelian Produk Online Shop Mayoutfit Di Kota Bandung," Universitas Telkom. Fakultas Komunikasi dan Bisnis. Program Studi Ilmu Komunikasi, Jurnal Lontar vol. 6 no 1, pp. 43-57, 2018.

[5] Witanti, Wina dan Renaldi Raiza, "Model Tatakelola Teknologi Informasi Dengan Pendekatan Malcolm Baldrige National Quality Pada Industri Tekstil,” Universitas Jenderal Achmad Yani. Jurnal Muara vol. 1, no.1, pp.39-47, 2017.

[6] Gasperzs, Vincent, “Ge Way And Malcolm Baldrige Criteria For Performance Excellent," Jakarta, PT Gramedia Pustaka Utama, 2007.

[7] Juariah, Resi, "Penerapan Kualitas Dengan menggunakan MBNQA," Bandung : STIE Ekuitas, Prodi S1 Manajemen. Banking and Management Review, vol. 5 no. 1, pp. 641-657, 2015.

[8] Syafaat, Achmad dan Abdul Wahid, "Strategi Pemasaran Produk Sepatu Menggunakan Metode Analisis SWOT Dengan Matrik IFAS Dan EFAS Di PT. Bagoes Tjipta Karya", Pasuruan: Universitas Yudharta Pasuruan, Prodi Teknik Industri Fakultas Teknik, Journal Knowledge Industrial Engineering (JKIE), vol. 07,no. 03, pp. 108-117, 2020.

[9] Nurlela dan Wan Junita Raflah, "Penggunaan Analisis SWOT dalam Mengembangkan Potensi Usaha Dodol Nenas Kelompok Tani Tunas Makmur Sungai Pakning”, Indonesia. Riau : Politeknik Negeri Bengkalis. Program Studi Administrasi Bisnis Internasional, Jurnal Inovasi Bisnis 9, pp. 1-6, 2021.

[10] Hidayatuloh, Sarif, “Analisis Strategi Pemasaran Jasa Perbaikan dan Instalasi AC Mobil Dengan Menggunakan Metode Malcolm Baldrige Pada PT Mitra Enviro Nusantara", Universitas Indraprasta PGRI (Unindra), Fakultas Teknik dan Ilmu Komputer, Jurusan Teknik Industri, Jurnal IKRA-ITH Ekonomika vol 3 no 3, pp-36-44, 2020. 